\title{
Indentation Fractography: A Measure of Brittleness
}

\author{
B. R. Lawn \\ National Bureau of Standards, Gaithersburg, MD 20899 \\ and \\ D. B. Marshall \\ Rockwell International Science Center, Thousand Oaks, CA 91360 \\ Accepted: August 30, 1984
}

\begin{abstract}
Indentation constitutes one of the most powerful test techniques for the systematic investigation of deformation and fracture responses in brittle materials. Indentations can be used to evaluate critical mechanical parameters (toughness, hardness, elastic modulus) with great simplicity and high accuracy.
\end{abstract}

Key words: crack initiation; crack propagation; erosion and wear; fractography; glass; indentation; radial cracks; strength.

\section{Introduction}

Indentation constitutes one of the most powerful test techniques for the systematic investigation of deformation and fracture responses in brittle materials. Indentations can be used to evaluate critical mechanical parameters (toughness, hardness, elastic modulus) with great simplicity and high accuracy. They can be used to introduce controlled cracks into strength-test specimens, and thence to obtain physical insight into failure mechanisms. They can be taken as a base for simulating "natural" surface damage processes such as particle impact, abrasive wear and machining. In short, indentations represent a model flaw system for quantifying a wide range of mechanical properties, and as such deserve detailed study.

Recourse to some of the review articles on the subject

About the Authors, Paper: B. R. Lawn, who is with NBS' Center for Materials Science, and D. B. Marshall, are physicists. Their work was sponsored in part by the U.S. Office of Naval Research, Metallurgy and Ceramics Program, and their paper is also appearing as a chapter in the Fractography of Glass, R. C. Bradt and R. E. Tressler, editors, Plenum Press, New York (in press).
$[1-8]^{1}$ reveals many facets of indentation analysis. For a start, contacts may be considered either "blunt" or "sharp," according to whether the local deformation prior to fracture is elastic or elastic-plastic. The latter, if relatively complex in its stress field characterization, presents us with some of the more interesting new phenomena in brittle fracture. Second, indentation events can occur under either equilibrium or kinetic conditions of deformation and fracture. Of these, the first lends itself more readily to detailed fracture mechanics formulation, but the second takes us closer to engineering design problems associated with "fatigue" (delayed failure) behavior. Again, distinction may be made between initiation and propagation stages in the contact fracture evolution. Propagating cracks are better understood because they develop in the contact far field, where high stress gradients smooth out. The ultimate crack configuration may nevertheless depend to a large extent on exactly where in the near field the initiation occurs, which in turn raises the question of availability of suitable starting nuclei (e.g., whether such nuclei are prepresent or have to be created by the contact process itself). We can devise many more categories for the general indentation phenomenology, e.g., in accordance

\footnotetext{
'Numbers in brackets indicate literature references at the end of this paper.
} 
with loading type (normal vs tangential) or loading rate (static vs dynamic), attesting to a wide diversity in underlying micromechanical processes.

Here we consider these facets in relation to the fractography of glass. We begin with surveys of blunt and sharp contact patterns, describing basic features of the respective morphologies and outlining the essential fracture mechanics procedures for quantifying these features. If we pay more attention to the sharp contact configuration, this is because of the relatively dominant place it has occupied in indentation testing over the past decade. We then consider the ways that contactinduced cracks evolve when subjected to an ensuing tensile stress, with their attendant implications on strength and flaws. Finally, we look briefly at how indentation experiments can be used to provide a base for modelling surface damage processes related to wear, machining, etc. In some instances we shall draw from studies on materials other than glass, both to add to our insight into certain fracture mechanisms and to help place the broad topic of indentation fractography into a wider perspective.

\section{Blunt Indenters}

If contact conditions remain entirely elastic up to the onset of fracture the indenter is deemed "blunt" [1]. The classical example is the Hertzian cone fracture produced by indentation of a flat surface with a relatively hard sphere [9]. A detailed description of the evolution of Hertzian fractures was first given by Frank and Lawn [10]. Initiation occurs from pre-existing surface flaws in the region of high tensile stress just outside the circle of contact; the ensuing crack encircles the contact and subsequently propagates downward and outward into its fully developed (truncated) cone configuration. As alluded to earlier, the second, propagation stage is much easier to understand, and so we shall deal with it first.

\subsection{Crack Propagation}

Under normal loading in an isotropic material like glass the Hertzian configuration assumes nearaxisymmetry [9-12]. Figure 1 shows top and section views of such a crack formed by a steel ball of radius $12.7 \mathrm{~mm}$ on soda-lime glass [13]. It is apparent that the configuration can be closely represented as the frustum of a cone. Once formed, the cone crack remains stable, although some further, subcritical extension can occur under sustained loading if moisture is present in the environment.

It is this stability of the fully propagating cone crack which makes for simplicity in the fracture mechanics analysis. Further increases in the indenter load over and above the critical value for "pop in" simply cause the cone to expand its circular base in a controlled manner [11]; i.e., the configuration satisfies the growth conditions for simple penny-like equilibrium cracks, for which there is a standard solution [14]

$$
P / c^{3 / 2}=A_{2} K_{\mathrm{c}}
$$

where $P$ is the load, $c$ is the characteristic crack size, $K_{\mathrm{c}}$ is the critical stress intensity factor for equilibrium extension (the "toughness") and $A_{2}$ is a dimensionless constant. Extensive data confirming the interrelation between $P$ and $c$ for glass are contained in References [1] and [14]. It will be noted that eq (1) is independent of any term relating to the initiation conditions; the propagation mechanics are determined exclusively by the properties of the far field.

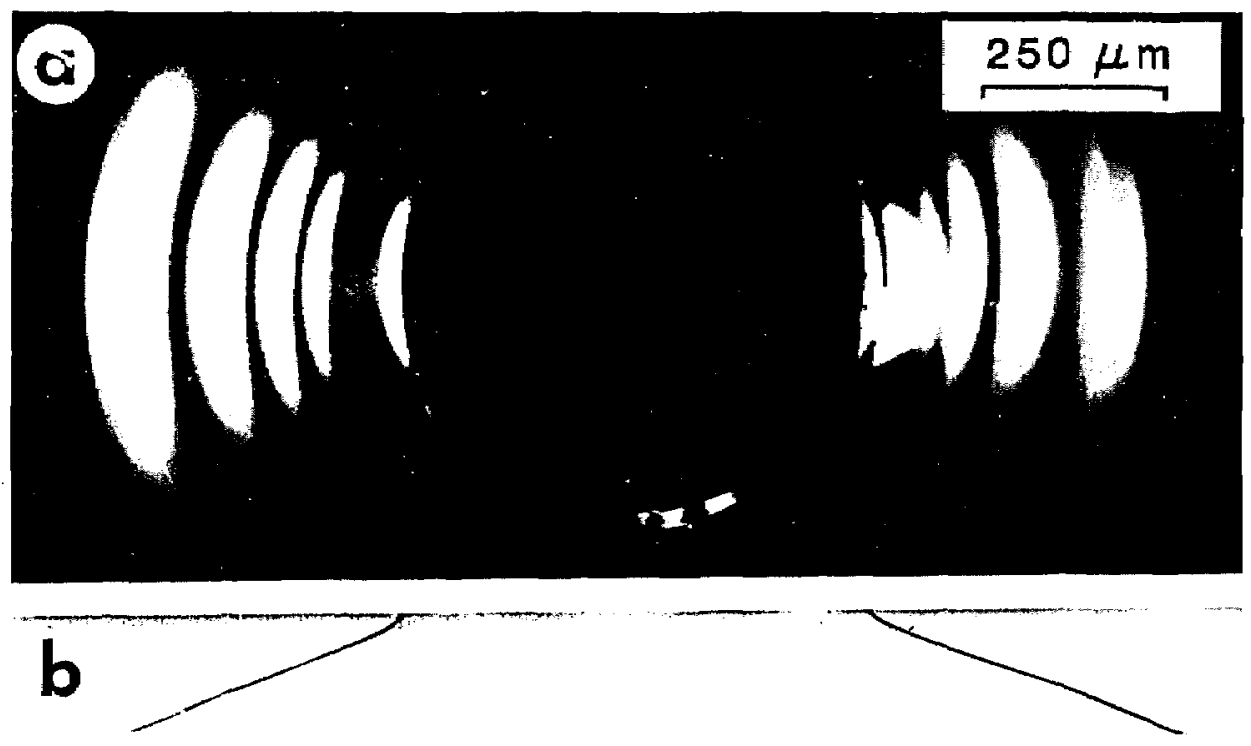

Figure 1-Hertzian cone crack in soda-lime glass: (a) view from beneath fully loaded specimen (light directed for specular reflection); (b) view in profile, after section-and-etch of unloaded specimen. After reference [13]. 


\subsection{Crack Initiation}

The precursor initiation micromechanics are more subtle because of the extremely high tensile stress gradients that exist about the contact circle $[1,10,15]$. It is not enough to say that initiation will occur when the surface tensile stresses reach the strength of the material; indeed, such a criterion leads to a totally incorrect relation between the critical contact load, $P_{c}$, and sphere radius, $r$. In terms of the modern fracture mechanics view, the crack evolves first as a shallow surface ring around the contact circle, and then extends downward, as the load increases, to a critical depth, at which point the system becomes unstable [10]. Implicit in this description is that there is a sufficient density of preexisting surface flaws to guarantee the first stage of initiation, for the elastic contact conditions provide no means for the self-generation of suitable crack nuclei in the optimal tensile regions. (Contrast the sharp-indenter case, later.) On the other hand, the actual size of the starting flaw should not be a critical factor in the initiation condition, because of the stabilizing effect of the inhomogeneous stress field.

Detailed fracture mechanics calculations confirm the above description, and lead to the following expression for the critical load to cone initiation $[1,10,15,16]$,

$$
P_{\mathrm{c}}=A_{1} r K_{\mathrm{c}}^{2} / E
$$

where $E$ is Young's modulus and $A_{1}$ is another dimensionless constant. As expected, eq (2) is not dependent on the starting flaw size. This flaw independence has been verified by tests on glass surfaces with different abrasion treatments [15]. The theory also predicts a linear relation between $P_{\mathrm{c}}$ and $r$, first observed empirically by Auerbach as long ago as 1891 [17]. "Auerbach's law," so called, had aroused much interest because, in combination with the Hertzian stress relation $\sigma \propto P / r^{2}$ $[1,9]$, it implies a size effect in the critical stress level, $\sigma_{c} \propto 1 / r$. (Reversing the argument, if fracture were to occur at a critical stress $\sigma_{\mathrm{c}}=$ const. we would expect $P_{\varepsilon} \propto r^{2}$, in clear violation of eq (2).) Note that the size effect is such that the necessary stress level increases as the sphere radius is reduced, suggesting the likelihood of some precursor "yield" as the indenter becomes "sharper."

Again, our formulation here is based on the assumption of ideal equilibrium conditions in the fracture process. When moisture is present subcritical crack growth can occur at $K<K_{\mathrm{c}}$, and cone pop-in thereby enhanced, in a rate-dependent way, at loads $P<P_{\mathrm{c}}$. Experimental studies of this environmental effect have been made $[18,19]$.

\subsection{Some Variants From Ideal Cone Fracture Configuration}

There are several variants in the blunt-indenter crack patterns that can be produced. We consider just two examples here.

First, if the test material is not isotropic, homogeneous, or free of pre-existing residual stresses, departures can occur from the ideal cone geometry, even under axial loading. This is demonstrated in figure 2 , for sphere indentations on single crystal silicon surfaces [20]. The broader feature of the surface ring crack is still apparent, but now the influence of crystallographic an-

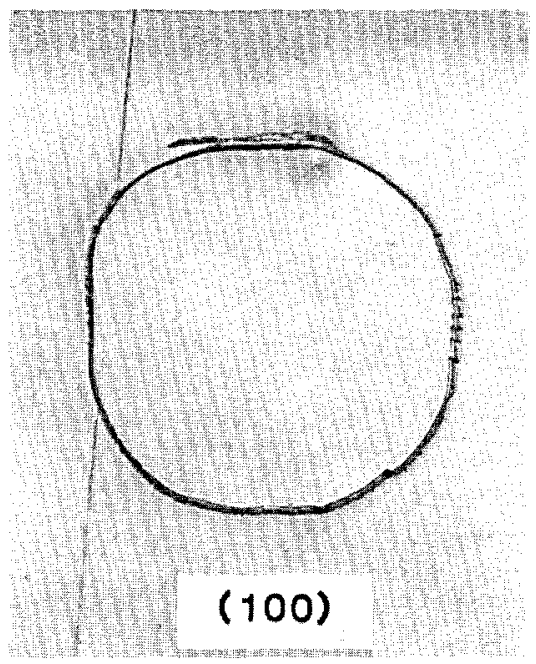

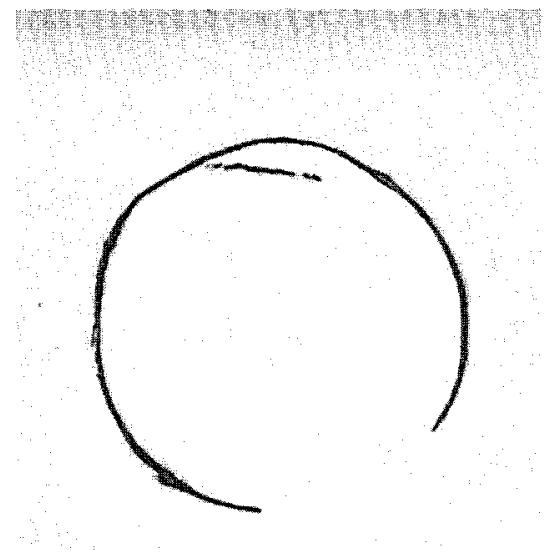

(111)

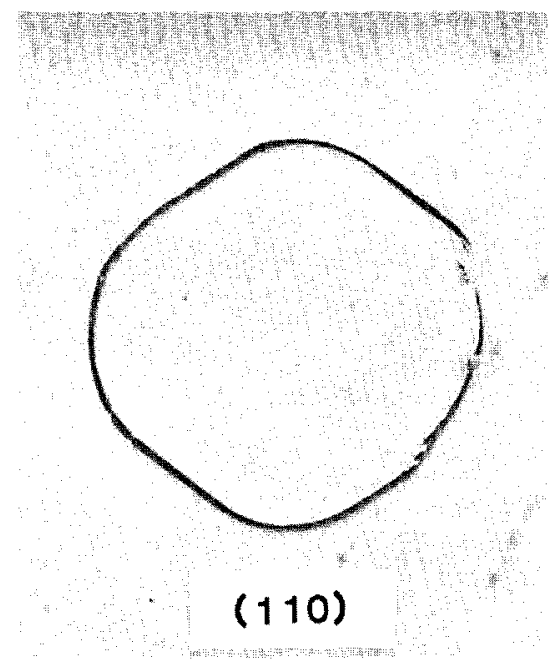

Figure 2-Hertzian fracture traces on silicon single crystals, for three surface orientations. Surfaces were etched after indentation. After reference [20]. 
isotropy has imposed itself on the patterns. In this case the crack path reflects the modifying effect of preferred $\{111\}$-plane cleavage on the tendency for the fracture to follow tensile stress trajectories. Such effects may be considered secondary insofar as eqs (1) and (2) are concerned, necessitating only a re-evaluation of the constants $A_{1}$ and $A_{2}$ [20].

In the second example, we consider the changes in the pattern that ensue when the indenting sphere is made to slide across the test surface with frictional tractions. Figure 3 shows a sliding-indenter track on soda-lime glass [21]. Now not one, but several, intermittent (partial) cone cracks are generated in the wake of the advan

a
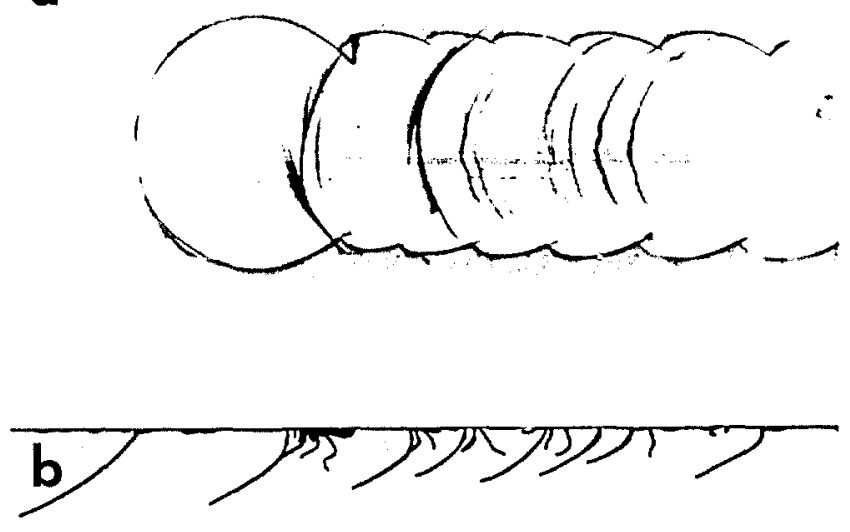

$500 \mu \mathrm{m}$

Figure 3-Partial cone crack damage track produced on soda-lime glass by sliding steel sphere (left to right), friction coefficient $f=0.1$ : (a) surface view; (b) profile view, after section-and-etch. After reference [21].

cing indenter. The superposition of a tangential loading force, quite apart from altering the stress trajectory configurations, profoundly enhances the level of tensile stress (principally at the trailing edge of the contact area) [22]. These changes are not felt so strongly in the propagation stage of fracture, since the far field remains relatively insensitive to near-contact boundary conditions. Indeed, the geometry of individual cracks in the sequence may be simply regarded in terms of a simple tilting of the normal cone, where the load axis is rotated vectorially by the superposition of the friction force onto the axial load component. Using this simplistic argument it can be shown that eq (1) transforms to

$$
P / c^{3 / 2}=A_{2} K_{\mathrm{c}} /\left(1+f^{2}\right)^{1 / 2}
$$

where $f$ is the coefficient of sliding friction. We may note the minor role of friction in this expression for crack size; for a fixed normal load $P$, a superposed sliding force at $f=1$ increases $c$ by only some $25 \%$. The initiation stage, however, is extremely sensitive to the friction-induced stresses. In this case the critical load equation, eq (2), is not so easily modified; solutions to the base fracture mechanics integration formulas have to be obtained numerically, and these solutions vary dramatically according to specific starting assumptions [23-25]. Suffice it to say that very small frictional forces can produce very large reductions in $P_{\mathrm{c}}$.

\section{Sharp Indenters}

We alluded in section 2.2 to the increased prospect of some pre-fracture yield at the contact zone as the indenter tip becomes "sharper." In the extreme of zero tip curvature we may expect the immediate contact stress field to be determined by the plastic rather than the elastic properties of the test material $[1,26]$. This transition in contact response is seen in the micrographs of figure 4, for indentations on arsenic trisulphide glass using (a) a steel sphere of radius $200 \mu \mathrm{m}$ and (b) a standard Vickers diamond pyramid. It is clear that the crack patterns are of a type totally different from that described in the previous section. In particular, the surface traces of the cracks are radially, rather than circumferentially, directed with respect to the contact area. The irreversible deformation has therefore significantly altered the nature of the tensile stress field. Moreover, it is possible to generate these same radial crack patterns on surfaces with the highest perfection, viz. pristine optical fibers [27], so the deformation process not only drives, but creates, the starting flaws. We consider these aspects of the fracture process below, following a similar course to that in our discussion of the blunt indenter case.

\subsection{Crack Propagation}

Let us now take a closer look at the crack pattern generated in sharp contact. If we take top and side views, as shown in figure 5 for a Vickers indentation on soda-lime glass, we find there are two operative crack systems [1]. Radial/median cracks (hereafter referred to simply as radial cracks) extend on median planes containing the load axis and an impression diagonal (where stress concentrations are highest). Lateral cracks extend from near the base of the subsurface deformation zone in a saucer-like manner, roughly parallel to the specimen surface. Under normal loading conditions both crack 
Figure 4-Radial crack patterns in arsenic trisulphide glass produced by (a) steel sphere (radius $200 \mu \mathrm{m})$ and (b) Vickers diamond pyramid.
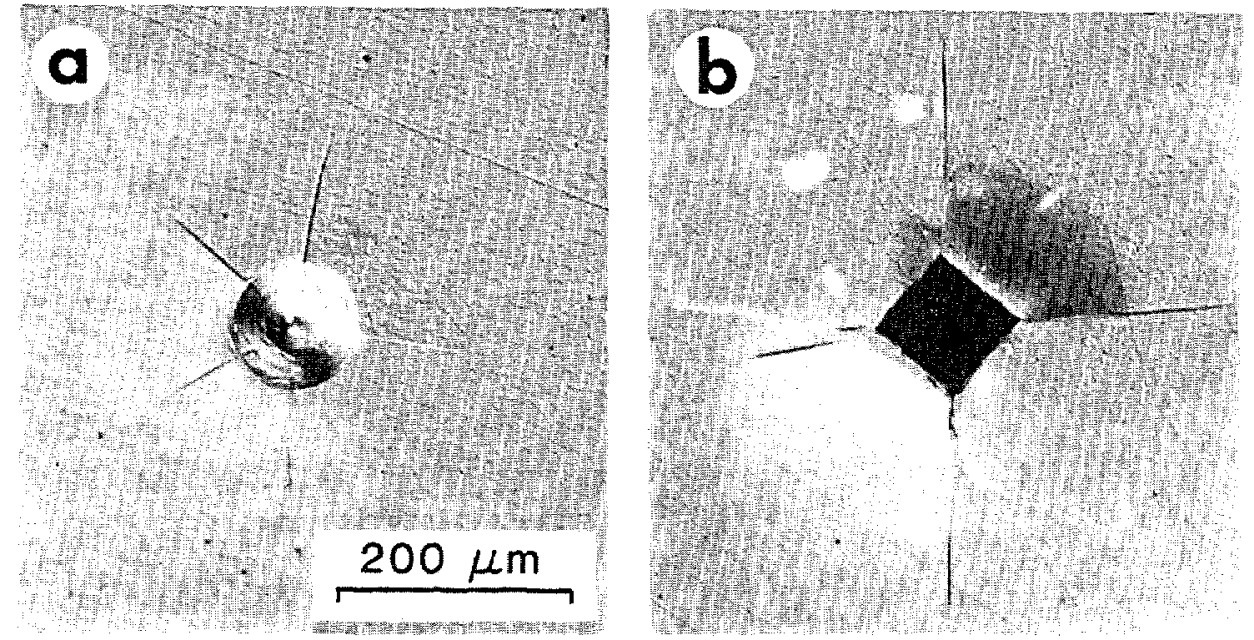

However, if we take the trouble to follow the crack

types attain a penny-like configuration, in that their fronts are near-circular (or semi-circular, in the case of radial cracks). Thus on outward appearances we might be led to conclude that the mechanics of crack propagation in the contact far field are really no different for sharp indenters than for blunt indenters.
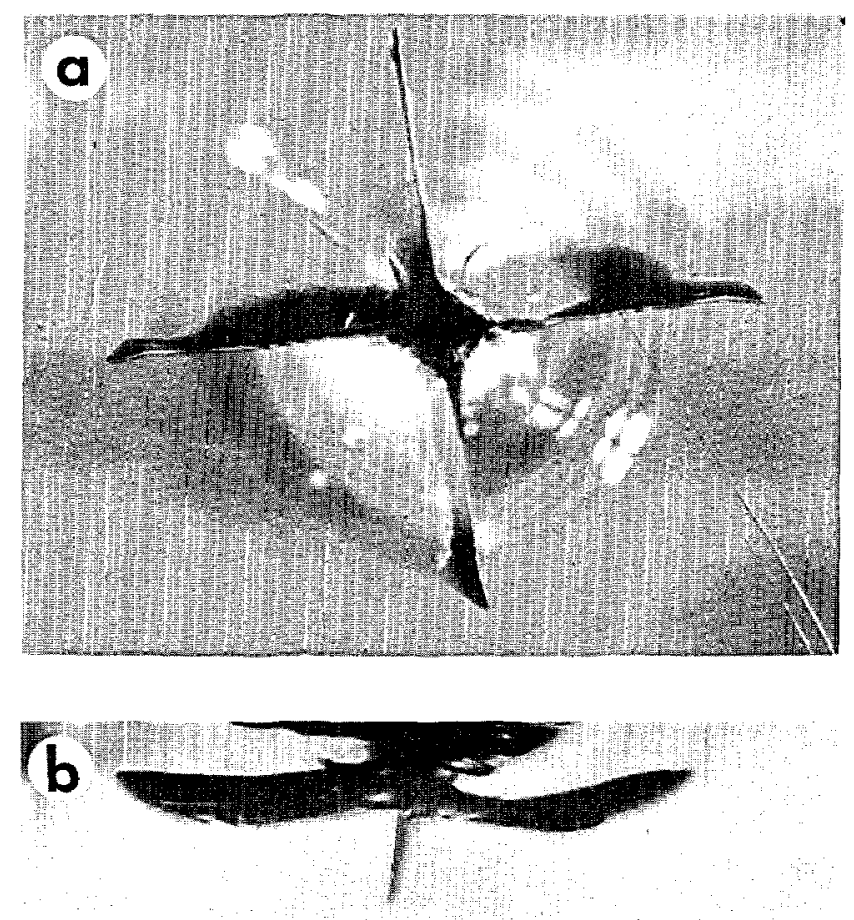

500

$\mu \mathrm{m}$

Figure 5-Vickers indentation in soda-lime glass: (a) surface view; (b) side view. Radial and lateral crack systems are evident. Courtesy B. J. Hockey. evolution during the actual contact cycle we discover some major differences between the two indenter types. The sequence of views in figure 6 , taken in polarized light from beneath a Vickers indentation in soda-lime glass, shows some of these differences [28]. It is apparent that the radial and lateral crack systems both develop primarily during the unloading half-cycle, and that this development takes place more or less continuously. (As the peak indentation load is reduced this tendency to development in the later stages of the cycle is enhanced, until at low loads, toward the threshold for initiation, the entire evolution is confined to a narrow load interval immediately prior to final withdrawal $[29,30]$.) It is also noted that the stress birefringence persists strongly in the last frame of the sequence. The sequence in figure 6 was shot in an inert (dry nitrogen gas) environment; on admitting laboratory air to the cracks at completion of the cycle the radial arms showed rapid and substantial post-contact growth, figure 7 . These observations indicate that it is now the inelastic rather than the elastic component that dominates the driving forces on the cracks.

Further clues to the evolutionary process can be gained by inspecting the radial crack surface in side view, e.g., after breaking an indented specimen [28]. Fortuitous crack-front markers, presumably due to perturbations in the indentation loading system, are evident in the example shown in figure 8. By correlating these markers with the radial traces in figure 6 , it can be deduced that crack extension during the loading halfcycle proceeds only in the downward direction, the surface component being almost completely suppressed. The explanation for this non-symmetrical growth is that the elastic component of the field, which is at full intensity at peak load, is essentially tensile below the surface but compressive at the surface. Unloading the in- 

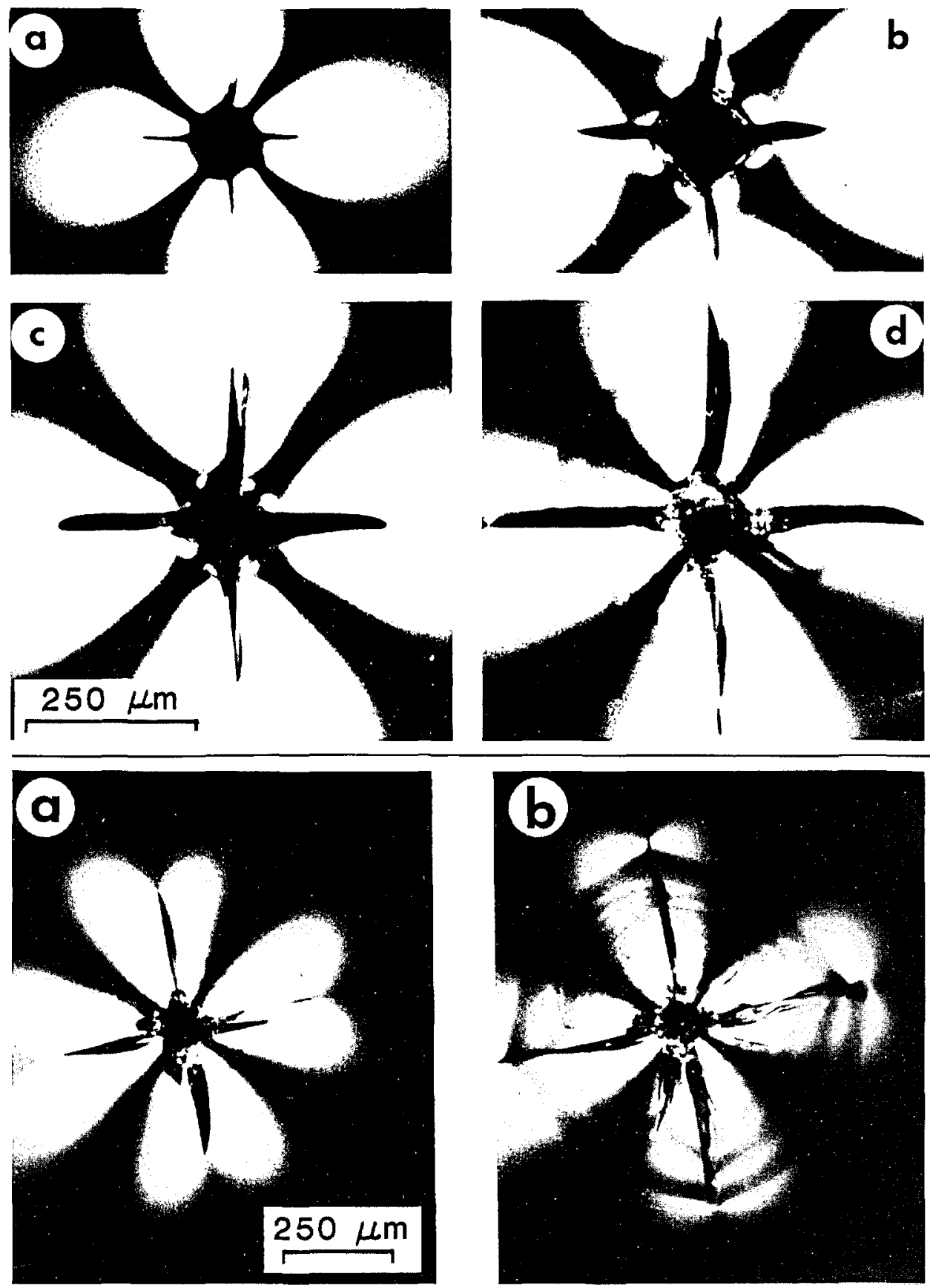

Figure 6-Vickers indentation in soda-lime glass, viewed from beneath indenter during loading cycle (polarized light). Sequence represents stages (a) half loaded, (b) full loaded, (c) half unloaded, (d) full unloaded. Lateral crack faintly visible in (d). After reference [28].
Figure 7-Same indentation pattern as in figure 6 , (a) immediately after completion of contact cycle, and (b) one hour later on exposure to air. denter is then equivalent to removing the elastic constraining stresses, leaving the crack system under the exclusive influence of the inelastic component of the field. This inelastic component acts to drive the cracks radially outward, accounting for the expansion into the ultimate symmetrical geometries on completion of the cycle.

Once this final state is achieved the cracks do indeed take on the universal propagation laws for penny-like configurations. Now, however, these laws must accom- modate the residual-stress component as an essential element of the description. This can be done by regarding the contact deformation zone as a central loading force on the crack systems, for which a scaling analysis yields the stress intensity factor

$$
K_{\mathrm{r}}=\chi P / c^{3 / 2}
$$

where $\chi$ is dimensionless constant. It will be noted that we have not yet specified how this residual driving force 


\section{Failure origin}

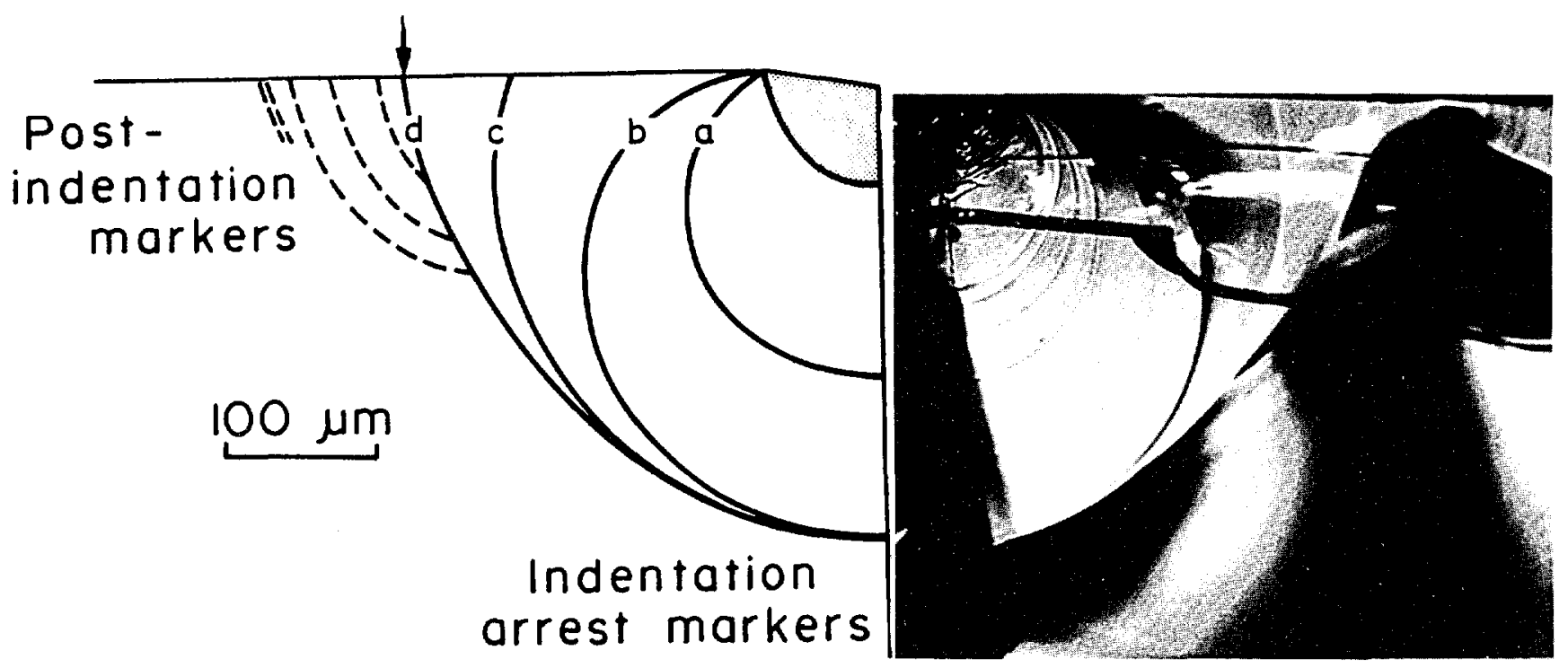

Figure 8-Same indentation as in figure 6, showing view of median crack plane after breaking specimen. Arrest positions marked correspond to stages (a) - (d) in figure 6 . After reference [28].

develops; the underlying physical processes lie "buried" in the scaling term $\chi$. Now, we have seen that the radial and lateral crack systems persist in a state of (stable) equilibrium throughout the unloading half-cycle, so we may set $K_{\mathrm{r}}=K_{\mathrm{c}}$ to obtain

$$
P / c^{3 / 2}=B_{2} K_{\mathrm{c}}
$$

for the immediate post-contact configurations, where we have put $B_{2}=1 / \chi$ to produce a formulation in direct analogy to eq (1) for cone cracks. Data on radial cracks in soda-lime glass and several other ceramics [31] show that this relation is well satisfied over a wide range of crack sizes, even in the suspect region of small cracks where the size is not much greater than that of the hardness impression (i.e., where the central point loading assumption might be expected to break down). Data on lateral cracks are not so extensive [32,33], and some doubt remains as to how well eq (5) represents the mechanics of this system.

We have acknowledged that, in adopting a scaling argument to derive eq (4), we necessarily sacrifice all insight into the physical meaning of the $\chi$ term. To obtain some of this insight, we may usefully observe the shape of the residual hardness impressions. The vital clue here is that these impressions show evidence of strong "elastic recovery" effects. With Vickers indentations [34] this recovery is manifest as a "springback" in the contact depth, or as a "pincushion" appearance of the surface impression. With Knoop indenters [35] it is apparent as a diminished minor axis relative to the major axis. The extent of the recovery correlates with the ratio of hardness to modulus, $H / E$. Figure 9 illustrates the point with examples of Knoop indentations in soda-lime glass and zinc sulphide [35], materials at the high and low end of this ratio spectrum, respectively; the impressions have the same nominal length in the two cases, but the recovery of the minor axis is clearly stronger in the glass. (In a material which shows no inelastic defor-
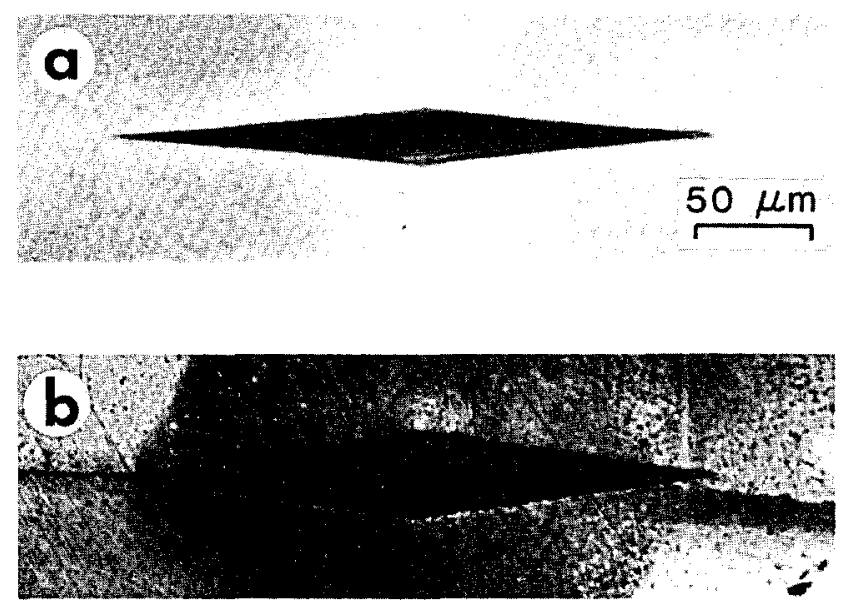

Figure 9-Knoop indentations in (a) soda-lime glass and (b) polycrystalline zinc sulphide. The glass shows stronger elastic recovery along the minor diagonal. (In unrecovered indentation, ratio of minor to major diagonal is 1:7.) After reference [35] 
mation, such as rubber, this recovery would, of course, be complete, and no impression would be left at all.) The importance of these recovery phenomena in the context of fracture is that they relate to the intensity of the residual strain field about the contact area, and thence to the $\chi$ term in eq (4). In particular, they identify the important material parameter, $H / E$, which is expected to enter the formulation of this term. Unfortunately, quantitative theories of the contact problem incorporating this parameter remain in their infancy, owing to the general intractability of elastic-plastic stress analyses. The only available solution thus far is for isotropic, homogeneous materials which deform by shearactivated, volume-conserving radial flow, a description fitting soda-lime and other "normal" glasses [36]; this solution is of the form $\chi \propto(E / H)^{1 / 2} \propto 1 / B_{2}$, [37] so the crack dimensions in eq (5) are no longer determined uniquely by the material toughness.

\subsection{Crack Initiation}

Below some threshold in the loading, radial and lateral cracks become suppressed. In glasses, the size of the hardness impression at which this threshold occurs is typically tens of micrometers, so it becomes difficult to observe the actual crack initiation processes by conventional optical microscopy. For this reason, we begin our discussion in this subsection with observations on another material, single crystal magnesium oxide, for which the critical events preceding fracture operate on a much larger scale.

Accordingly, figure 10 shows Vickers indentations on the (001) surface of magnesium oxide [38]; the views in (a) and (b) differ only in that the axis of the indenting pyramid has been rotated through $45^{\circ}$. Radial cracks are evident as before, but note that these cracks do not extend beyond the well-defined slip-plane traces on the specimen surface. Now magnesium oxide is a relatively "soft" material (i.e., low $H / E$ ), so the elements of flow (in this case, dislocations) which accommodate the penetrating indenter extend well beyond the immediate hardness impression. The cracks we see are produced by intersection of the slip planes, in much the way as envisaged in the classical Cottrell "pile-up" model $[39,40]$. In other words, we are witnessing the initiation, and not the propagation, stage of fracture. We may reinforce this conclusion by noting that the cracks extend in identical directions for the two indenter orientations in figure 10; it is the slip-trace configuration, and not the alignment of the stress-concentrating contact diagonals, which dictates the fracture geometry. Moreover, the cracks lie on $\{110\}$ planes, whereas the normal cleavage plane for fully propagating cracks in the rocksalt structure is $\{100\}$. Under such conditions our formulation for well-developed patterns in section 3.1 no longer has any basis and we must turn our attention to the mechanics of the precursor deformation process.

It is interesting to investigate how far, if at all, we may carry this description over to glass. We have mentioned the experimental difficulties associated with the relatively small scale of the hardness impressions in the initiation region. These difficulties are compounded by the relatively high value of $H / E$ for glass, corresponding to a much greater confinement of the deformation elements within the immediate contact zone [37]; our observational techniques must therefore be capable of providing information on subsurface events. Some progress has nevertheless been made in this direction, notably by the examination of sectioned indentations using high resolution microscopy [30,41-43]. Examples
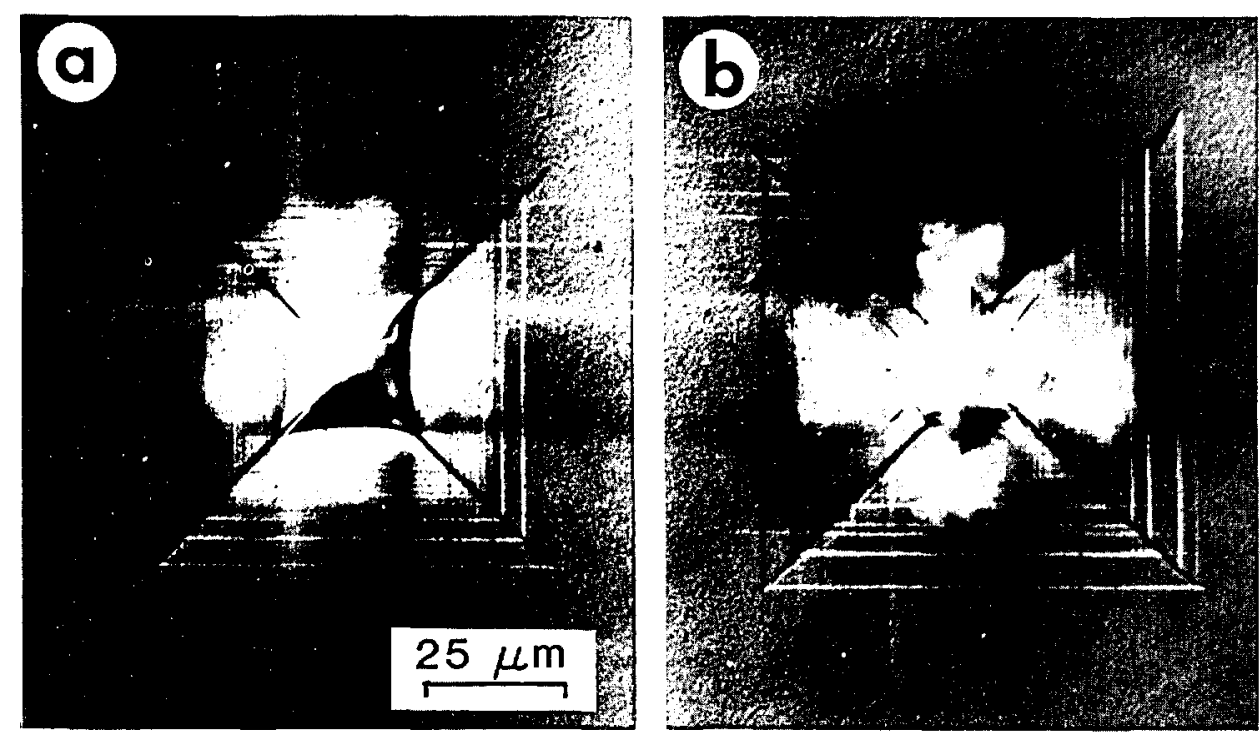

Figure 10-Vickers indentations on (001) surface of single crystal magnesium oxide. Edges of micrographs are purallel to $\langle 100\rangle$ directions. Courtesy B. J. Hockey. 
of the pertinent detail that can be revealed in this way are shown in figure 11(a) and (b) for soda-lime and arsenic trisulphide glass, respectively. There are traces of "shear faults" on the specimen surfaces, somewhat analogous to the slip lines in figure 10 , but now without crystallographic features; the slip follows trajectories of maximum deviatoric stress in the near-contact field [41]. The fact that we are looking at an amorphous material here tells us that the fundamental faulting process is radically different from that generally described in terms of dislocation glide; not only does the classical concept of a dislocation Burgers vector break down in the non-crystalline structure but the operative shear stresses (as inferred from the hardness value) are close to the theoretical cohesive limit.

Whatever the true nature of the shear faulting mechanism, it is apparent that the process is severely disruptive, and therefore capable of generating centers of intense stress concentration for crack nucleation and growth. Indeed, close scrutiny of micrographs of the kind shown in figure 11 shows that one can invariably associate the initiation point of the radial and lateral cracks with one or more (usually intersecting) faults. Arguing along these lines, one may construct a simplistic, two-step model for the initiation [30]: in the first step, the stress concentration at the edge of shear fault reaches a sufficient intensity to nucleate an embryo microcrack; in step two, the microcrack grows to some critical instability point, whence pop-in ensues. For equilibrium fracture conditions the initiation relation may be determined once more by scaling principles [44],

$$
P_{\mathrm{c}}=B_{\mathrm{l}} K_{\mathrm{c}}^{4} / H^{3}
$$

with $B_{1}$ another dimensionless term. It is interesting to compare this result with its counterpart for cone cracks, eq (2); note that $H$ replaces $E$ as the controlling material contact parameter, reflecting the change from elastic to inelastic near-field conditions (notwithstanding the fact that $B_{1}$, for the same reasons as discussed in relation to $B_{2}$ in section 3.1, will depend on $H / E$ ).

As with cone cracks (Section 2.2), radial and lateral cracks are susceptible to enhanced initiation at $P<P_{c}$ when moisture is present in the environment. Indeed, this enhancement can be substantial, with reductions of over two orders of magnitude in the threshold load when the indentation test is run in water [45]. Moreover, the initiation may now occur after, rather than during, the contact cycle (once more attesting to the vital role of the residual stress component), indicating that the effect of the hydrolytic interaction is rate dependent. The theoretical description is complex, for it can involve either of the two steps referred to above in connection with eq (6), and these steps are not easily differentiated in the kinetic data [30].

\subsection{Some Variants From the Ideal Sharp Indenter Pattern}

Let us look at some of the ways in which the somewhat simplistic descriptions in the previous subsection require modification when dealing with non-ideal contact systems.

Perhaps the most important of these non-ideal systems is that involving "anomalous" glasses, of which fused silica is the archtype [36]. These are glasses which deform by densification rather than by volume-conserving
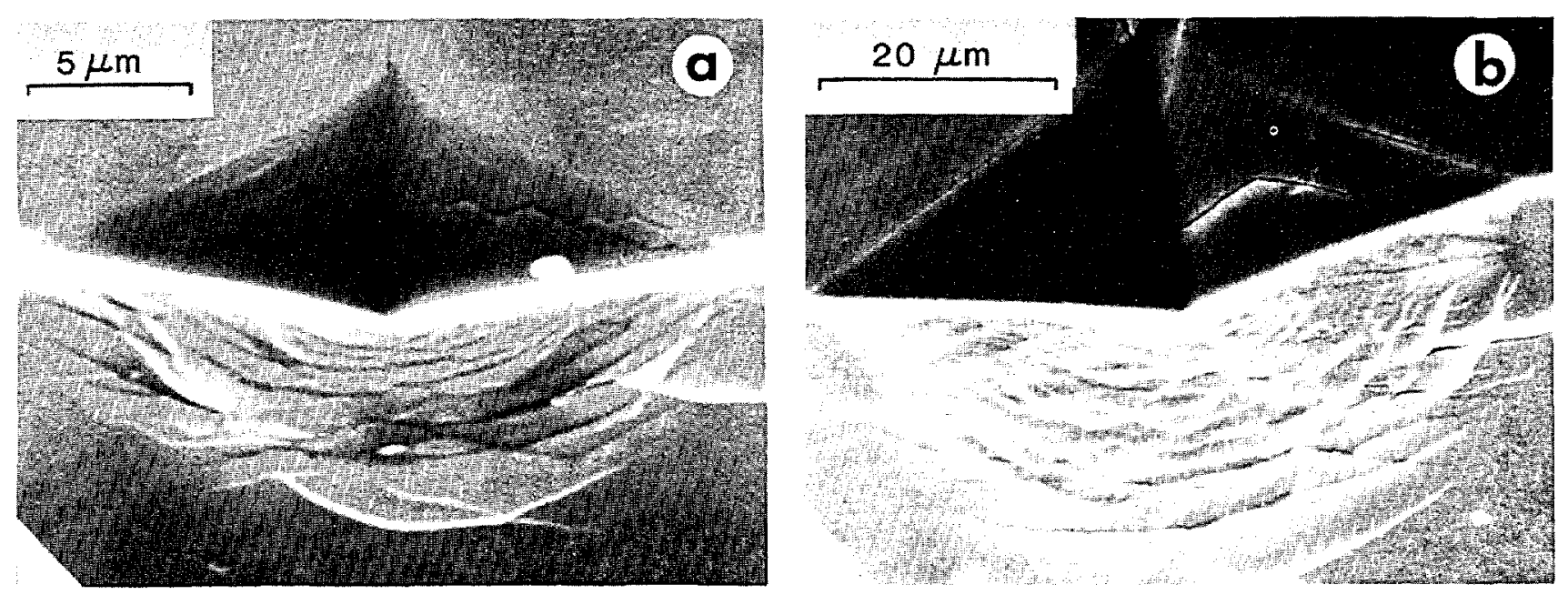

Figure 11 - Scanning electron micrographs of near-threshold Vickers indentations in (a) soda-lime and (b) arsenic trisulphide glasses. Specimens prepared by indenting across preexisting hairline crack in glass surfaces, then breaking in order to obtain half-surface and section views. After references [8] and [43]. 
flow. Figure 12 compares Vickers indentations in sodalime and fused silica glasses. The patterns for the two glasses show clear differences, particularly in the nearcontact region. It appears that in fused silica the intense local displacements induced by the penetrating indenter generate the same kind of shear offsets at the contact surface, but that these do not extend downward into the material as they do in soda-lime glass [45]; anomalous glasses do not contain the component of ionic modifiers thought necessary to produce "easy paths" for slip, along connected regions of terminal bonds [46]. Hence the silica structure accommodates the indentation volume by "collapsing" its structure. This densification mode is less disruptive, because it does not involve rupture, but rather realignment, of the network bonds [46]. Accordingly, the intensity of the residual contact field is much reduced in the anomalous glasses (a fact readily evident as a diminished birefringence in views of the kind shown in figure $6[36]$ ). In terms of eqs (5) and (6), this means one must completely re-evaluate the way the coefficients $B_{1}$ and $B_{2}$ relate to $H / E$, although the forms of the loād/crack-size dependence remain unaffected. Another manifestation of the reduced driving force for radial and lateral cracking in anomalous glasses is the tendency for some cone cracking to occur, as in figure 12(b), suggesting that the contact field in this case may be more properly viewed as a hybrid of the blunt and sharp extremes.

As a second example, we consider how the crack patterns may be affected by inhomogeneities in the material system. This could be an important consideration in the development of new glasses with porosity or included phases. The potential for significant crack-
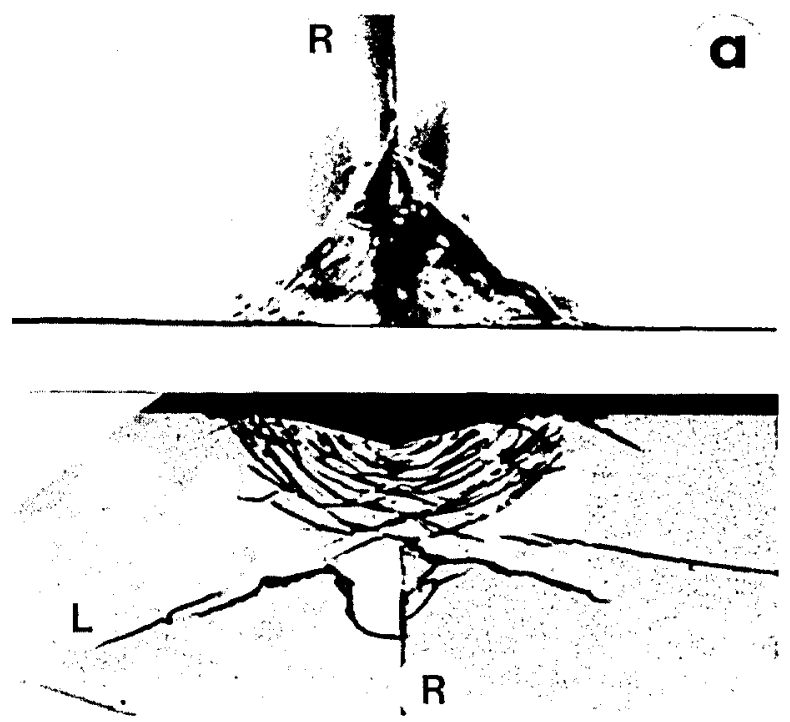

microstructure interactions can be most readily demonstrated by reference to figure 13 , which shows Vickers indentations in alumina of three different grain sizes [47]; the sequence represents systems in which the radial cracks are (a) much larger than, (b) comparable with, and (c) much smaller than the scale of the microstructure. In cases (a) and (c) the crack patterns are well defined, as though the material were effectively homogeneous, but in (b) it is difficult to distinguish any true radial cracks at all. The implication here is that any microstructural elements which exist on a scale comparable with that of the contact itself can have a profound influence on the qualitative, as well as the quantitative, interpretation of the indentation crack patterns.

Finally, brief mention may be made of the effect of translating a sharp indenter across the test surface, effectively transforming the contact configuration from "point" to "line" loading [48]. Such a transformation changes the distribution, but not the nature, of the residual driving force on the crack. We show in figure 14 an end view, in polarized light, of a line flaw in sodalime glass to re-emphasize that this residual driving force is by no means a minor factor. An analysis of the linear flaw geometry leads to the result $[48,49]$

$$
P / c=B_{2}^{\prime} K_{\mathrm{c}}^{2}
$$

as the analogue of the point-flaw relation, eq (5).

\section{Indentations as Controlled Flaws in Strength Analysis}

Perhaps the most powerful of all applications of indentation fracture mechanics is in the analysis of
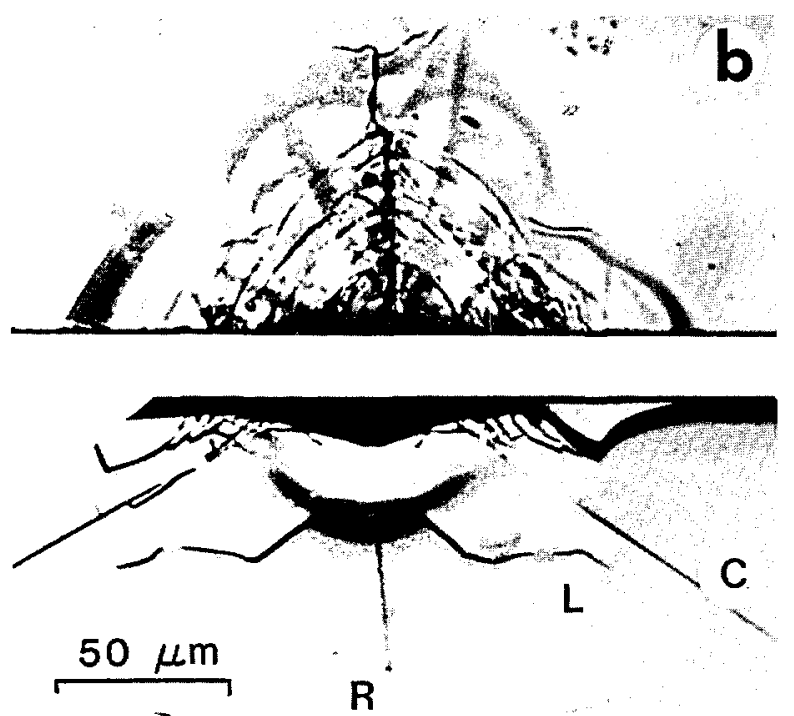

Figure 12 -Vickers indentations in (a) soda-lime and (b) fused silica glasses in half-surface (top) and section (bottom) views. (Specimens prepared in same way as those in Fig. 11.) Crack components indicated: R, radial; L. lateral; C, cone. After reference [36]. 

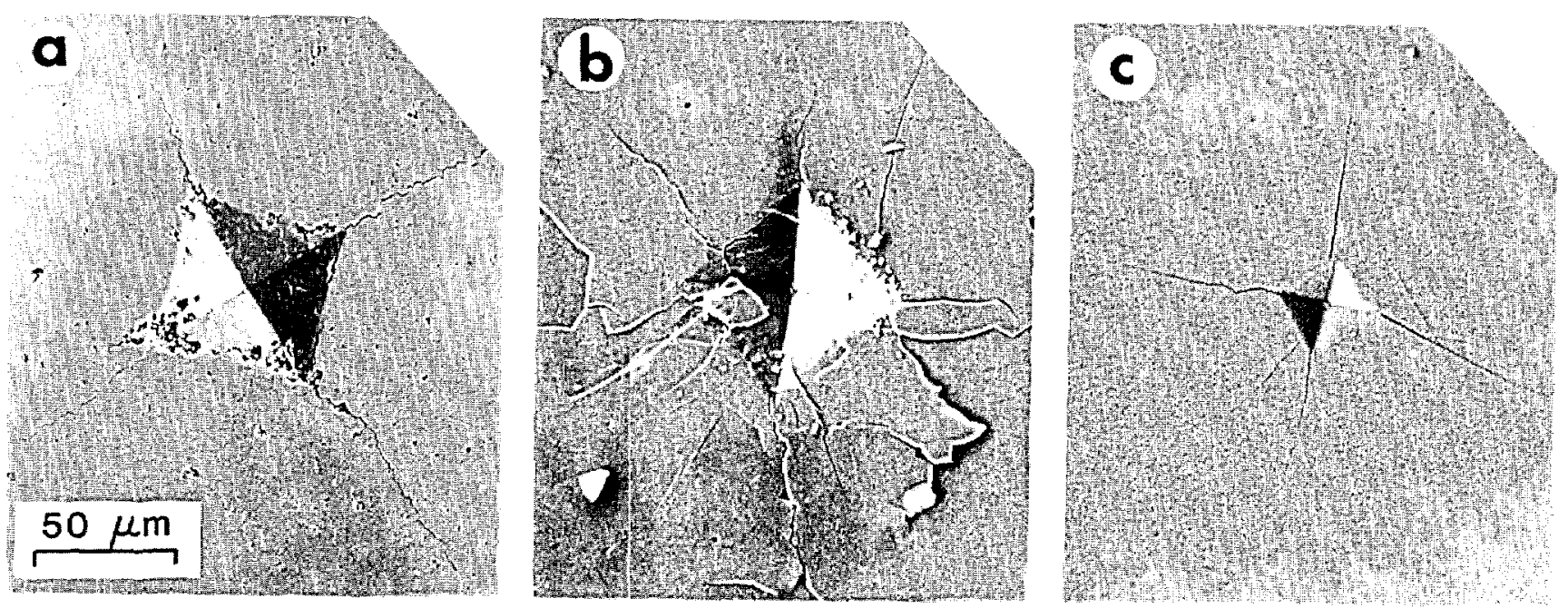

Figure 13-Scanning electron micrographs of Vickers indentations in three aluminas, (a) grain size $3 \mu \mathrm{m},(\mathrm{b})$ grain size $20 \mu \mathrm{m}$, and (c) single crystal (sapphire). After reference [47].

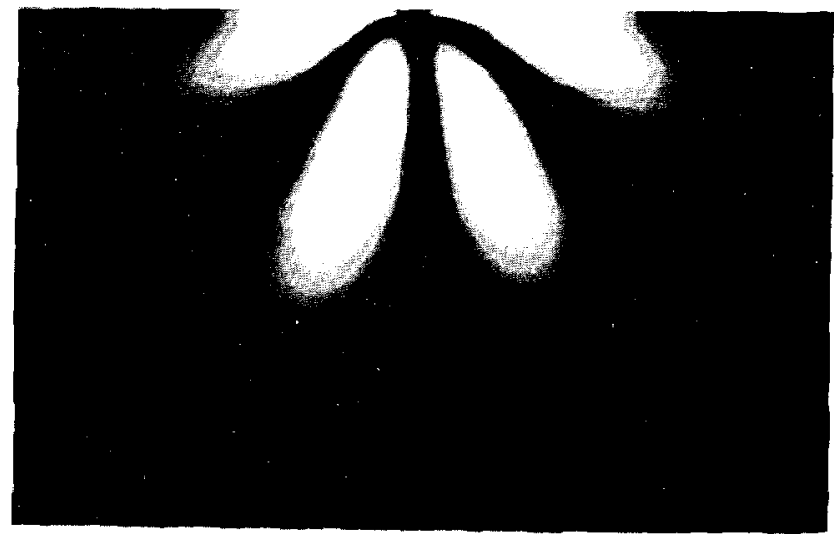

Figure 14 - Line flaw in soda-lime glass, produced by tungsten carbide glass-cutting wheel. End view, in polarized light, showing residual stresses about track. After reference [48].

strength properties of brittle materials. For those concerned with materials evaluation, indentation provides a means of determining intrinsic fracture parameters withsimplicity and accuracy. We shall make only brief reference to this aspect of the work in the sections below. Indentations can also be used to simulate the way in which naturally occurring surface flaws respond to applied stresses. It is here that most of our attention will be directed. We shall find that the results of controlledflaw studies contain some surprises, particularly in relation to the time-honored Griffith concepts of strength.

\subsection{Crack Morphologies in Failure}

Let us begin with a survey of the fracture morphologies that result when the different indentation crack types are taken to failure in applied tensile loading. Our aim in this subsection is to make the reader aware of some of the complications that may need to be considered when interpreting strength data. In this endeavor, we confine ourselves strictly to qualitative details.

Our first example pertains to the failure from conetype cracks. Figure 15 shows such a failure, in this case from a sliding sphere track in soda-lime glass [21]. The test was carried out in an inert environment, so that moisture-assisted subcritical growth did not occur. Failure initiated from the base of one of the deeper cone cracks, and was spontaneous at the critical stress. In the end view of figure 15 we see large steps flanking the initiation point and curving around the cone base toward the specimen surface. The resulting intersection at the surface does not have a linear trace, but tails into a cusp which points along the original direction of sliding. It is clear that the fracture surface is far from planar, indicating the complexity in growth evolution that a curvilinear flaw will generally have to undergo as it attempts to align its plane normal to the tensile axis. In other words, we are dealing with a "mixed mode" fracture configuration, where shear components contribute to the crack driving force.

With radial cracks this issue of mixed mode loading can be avoided by taking care to orient the indenter so that principal median plane (i.e., the plane containing the long diagonal in the case of Knoop indenters, or either of the diagonals in the case of Vickers) coincides with that of the maximum tensile stress in the subsequent failure test. Now, however, a new and more farreaching complication becomes evident. We see this in figure 16, which shows micrographs of Knoop indentations in silicon nitride before and during application of the stress (in this case, flexural) which leads to failure 

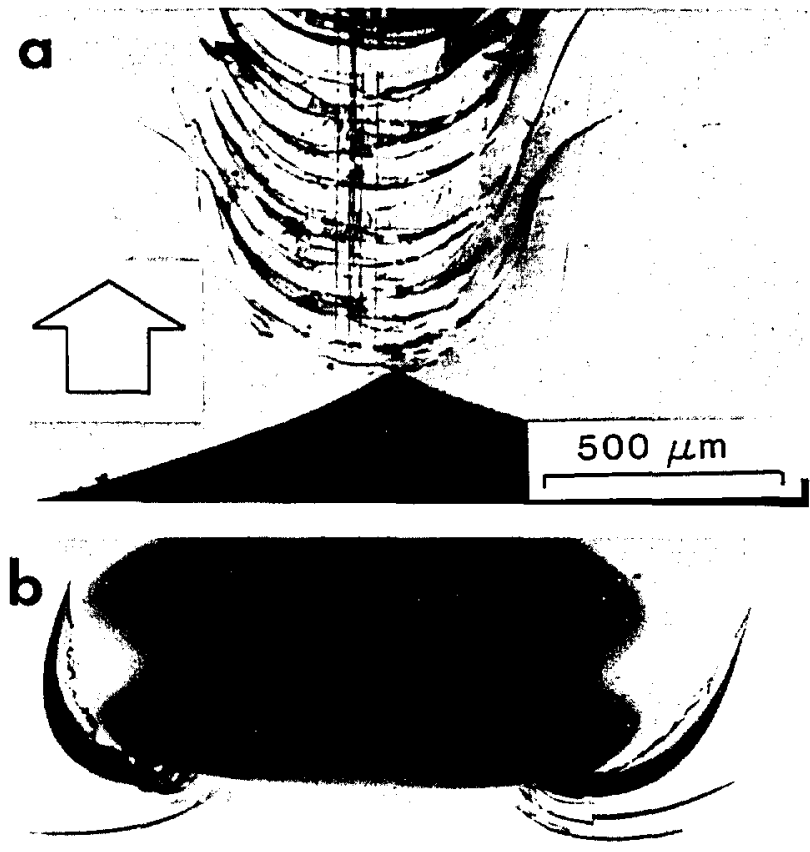

Figure 15-Failure from sliding-sphere track in soda-lime glass (friction coefficient 0.5 ): (a) surface view; (b) end view of fracture surface. In this case failure initiated from the first partial cone in the track. After reference [21].

[50]. The radial crack arms have clearly extended prior to failure, contrary to the conventional notion that the failure should occur spontaneously from an otherwise invariant flaw configuration. Lest it be argued that such precursor extensions could be due to moisture-assisted slow crack growth effects (and we shall indeed demonstrate below that slow crack growth can have a profound influence on the failure conditions), it is pointed out that the silicon nitride used in this work was chosen precisely because it is immune to such effects [50]. The same kind of response is obtained for silicate glasses tested in inert environments (vacuum, dry nitrogen) [51]. In view of our observations earlier concerning the evolution of radial cracks during the unloading stage of the indentation cycle (Sec. 3.1), we are led to conclude that the prior growth stage is a manifestation of the stabilizing influence of the residual contact stresses.

If the radial crack is not oriented normal to the tensile axis, or if the failure test is not conducted under equilibrium conditions, the added presence of mixed-mode and slow crack growth effects makes interpretation of the residual stress contribution somewhat less straightforward. These two complicating factors are apparent in figures 17 and 18, for Vickers indentations on sodalime glass. In figure 17, the radial cracks were oriented to lie at $45^{\circ}$ to the ensuing stress, which was applied to

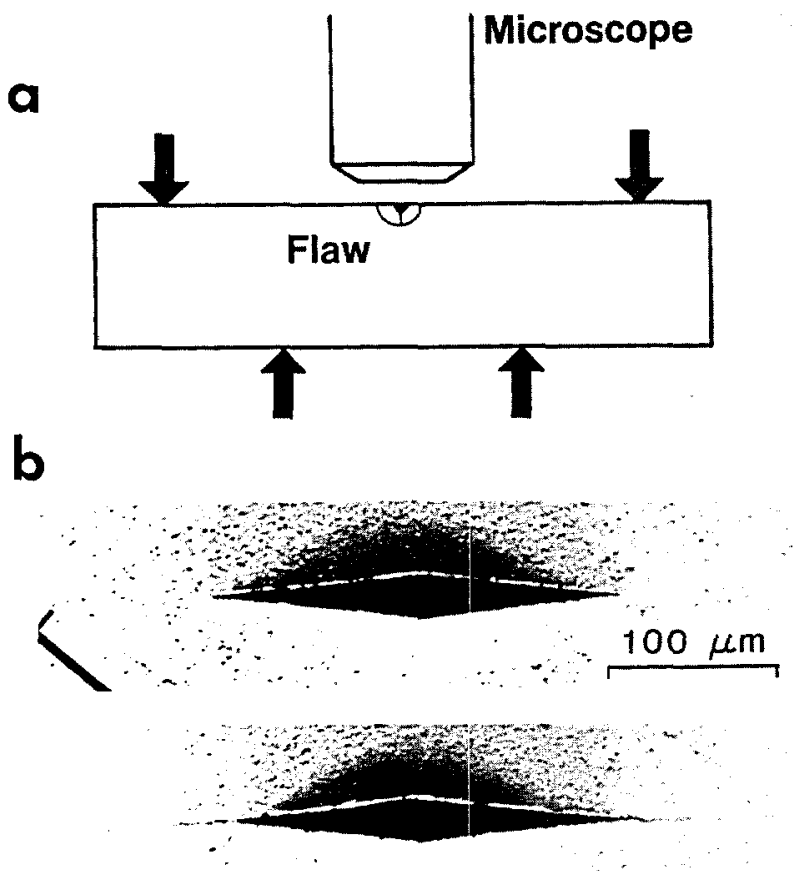

Figure 16-Growth of radial cracks from Knoop indentations in hotpressed silicon nitride: (a) strength test arrangement; (b) crack pattern prior to and during stress application. After reference [50].

a level a little below that needed to cause failure [52]. The characteristic precursor growth is again in evidence, but note that the tendency for alignment of the cracks onto a plane of maximum tension is realized gradually during this growth stage. All theories of crack extension from inclined flaws based on the notion of spontaneous failure predict that this reorientation event should occur abruptly, producing a distinct kink in the surface crack path [52]. In figure 18, the radial cracks were oriented normally, but were taken to failure in water at a prescribed stressing rate; the two cases shown represent specimens (a) annealed before strength testing, to remove the residual stresses, and (b) tested in the asindented state [53]. Although the pre-failure extension is well in excess of that observed in inert-strength tests, demonstrating that slow crack growth is no longer a minor factor, it is far more pronounced in the specimen where residual stresses remain operative.

All this is to emphasize the intractability of an exact strength formulation for materials which fail from natural flaws. Traditional theories of strength are based on highly simplistic descriptions of such flaws: given that the flaws do indeed have the nature of true microcracks (and even this may be open to question, particularly as strength levels approach the theoretical limit imposed 
by cohesive forces, as they do in optical fibers), it is generally taken that the mode of failure is strictly tensile and, more significantly, that the sole driving force acting is that due to the applied loading system. It needs to be made clear that these descriptions are not based on any direct experimental evidence; natural flaws are small, rarely larger than $100 \mu \mathrm{m}$ in maximum dimension, and the location of the critical member in a large population is virtually impossible to predetermine. Fractography in such cases is restricted to post-failure analysis, which is severely limited in the information it can provide on flaw history.
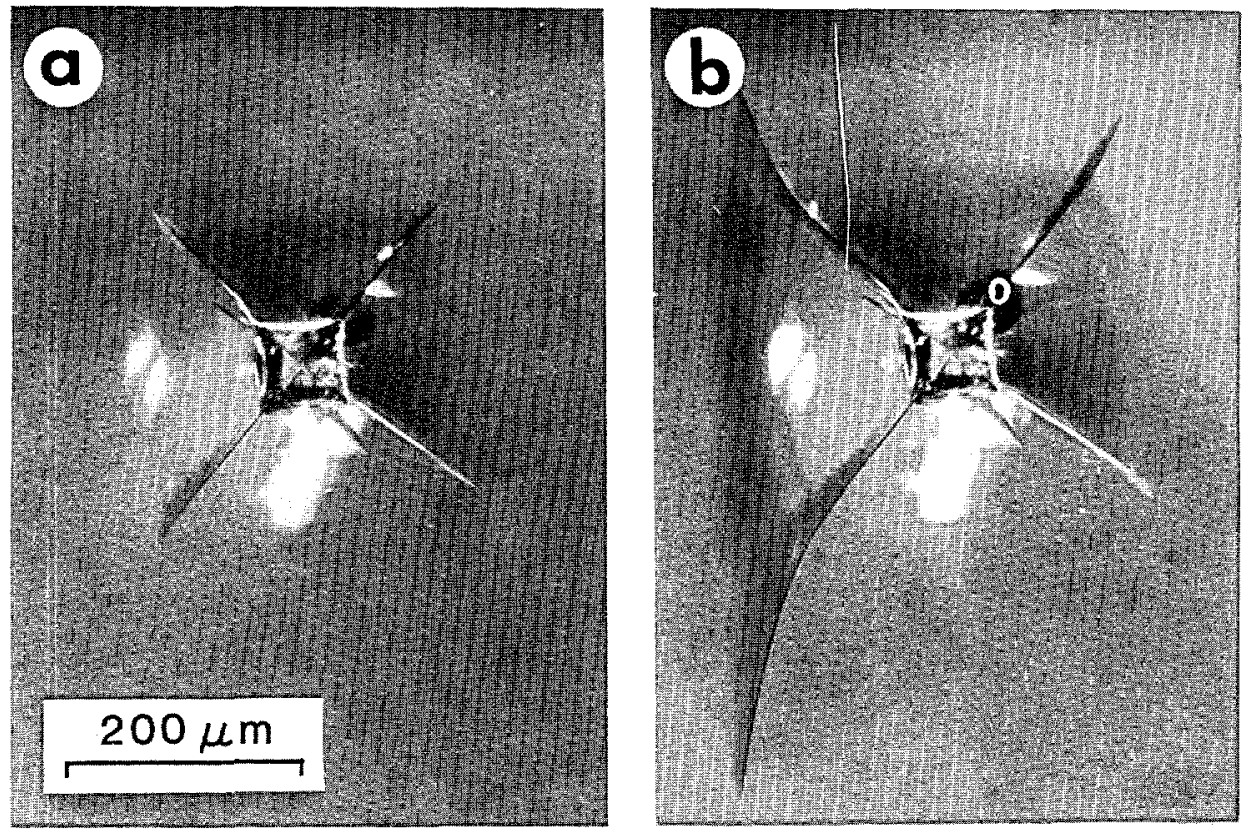

Figure 17-Growth of radial cracks from Vickers indentations in soda-lime glass during strength test: (a) prior to stressing; (b) during stressing. Indentation in this case was oriented with radial arms at $45^{\circ}$ to prospective tensile axis (horizontally directed in this diagram) so as to produce mixed-mode loading.

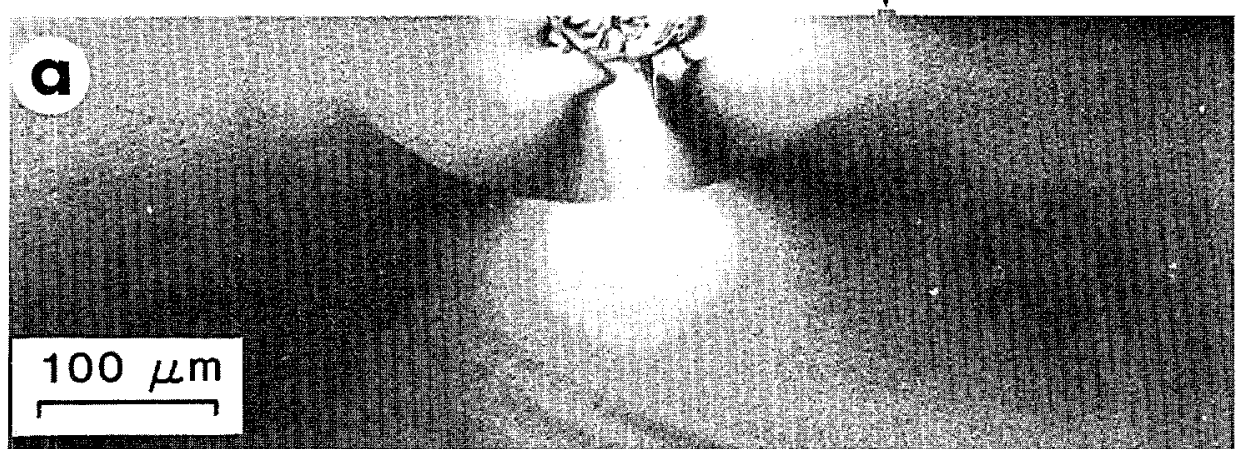

$+$
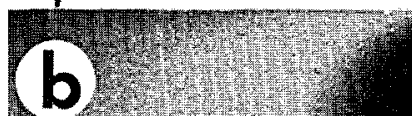

)
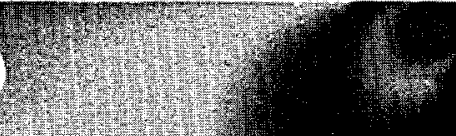

整

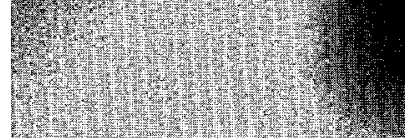

W

1)

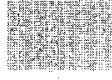

Annealed

As-Indented
Figure 18-Fracture surfaces of Vickers-indented glass broken in water at fixed stressing rate. Contact load used to produce the indentations in the two cases illustrated was the same. Arrows designate points at which failure originated in the strength tests. After reference [53]. 


\subsection{Strength Formulations}

We have implied that the growth of flaws to failure is generally more complex than conventional strength theories would have us believe. In this subsection, we examine how the complicating factors, particularly those associated with residual contact stresses, may be incorporated into a broader fracture mechanics analysis.

The generalization may be achieved by writing the stress intensity factor for indentation cracks in the form $[5,51,54]$

$$
K=\psi \sigma_{a} c^{1 / 2}+\chi P / c^{3 / 2}
$$

where $\sigma_{\mathrm{a}}$ is the applied stress and $\psi$ is a dimensionless, crack geometry term; the second term on the right of eq (8) is the residual component defined previously in eq (4). The condition for failure under equilibrium conditions is that $K=K_{\mathrm{c}}$. In the traditional view the residual term is ignored, whence instability occurs at the initial crack size $c=c_{0}$ when $\sigma_{\mathrm{a}}=\sigma_{0}$, say,

$$
\sigma_{0}=K_{\mathrm{c}} / \psi c_{0}{ }^{1 / 2}
$$

This result is applicable to cone cracks, or to radial cracks after annealing, with due allowance for mixedmode effects in the $\psi$ term [21,52]. However, for nonzero residual stresses instability does not occur until the crack has first extended from $c=c_{0}$ to a critical configuration $c=c_{\mathrm{m}}$, at which $\sigma_{\mathrm{a}}=\sigma_{\mathrm{m}}$; this instability may be determined from the equilibrium form of eq (8) by putting $\mathrm{d} \sigma_{\mathrm{a}} / \mathrm{d} c=0$, thus

$$
\begin{aligned}
& \sigma_{\mathrm{m}}=3 K_{\mathrm{c}} / 4 \psi c_{\mathrm{m}}{ }^{1 / 2} \\
& c_{\mathrm{m}}=\left(4 \chi P / K_{\mathrm{c}}\right)^{2 / 3} .
\end{aligned}
$$

Herein lies the formal description of the precursor stable growth stage referred to earlier in relation to virgin (non-annealed) radial crack systems, e.g., figure 16. It may be pointed out that eqs (9) and (10a) are of nearidentical form (notwithstanding the factor 3/4) insofar as the relation between strength and critical flaw size is concerned [55], so the intricacies of pre-fracture flaw response may well pass unnoticed in the usual kind of fractographic observations. Some of the newer flaw detection techniques which are capable of characterizing flaw configurations during testing (e.g., acoustic scattering [54]) seem to suggest that the second category above is far more widespread than previously suspected, especially for surfaces with a contact-related history (machining, abrasion damage, etc.).
This influence of residual contact stresses can show up in subtle ways, as in the aging of glass. In a classical early study of this phenomenon, Mould showed that the strength of freshly abraded glass surfaces tended to increase gradually, typically by $30-40 \%$, on prolonged exposure to water prior to breaking [56]. The prevailing view of this increase is that the crack tips are somehow "blunted" by the environmental interaction. However, if these studies are repeated under the same aging conditions, but with Vickers flaws instead, we find that strengthening occurs only while the cracks are actually extending [53,57], e.g., as in figure 7. This means, of course, that the aging process cannot be associated with any explanation in which crack rounding dominates crack lengthening. Now while the growth of the radial crack is not expected to affect the strength (since $\sigma_{\mathrm{m}}$ in eq (10a) depends only on the critical crack size $c_{\mathrm{m}}$ and not on the initial crack size $c_{0}$ ), the growth of the lateral crack can play an important role by relaxing the residual driving force on the system, i.e., diminishing $\chi$ in eq (10b). This interpretation is supported by the absence of any analogous strengthening on abraded or indented surfaces which have been annealed prior to breaking $[56,57]$. The results here bear on the fundamental nature of crack tips, implying that the intrinsic "sharpness" of flaws is not easily negated, even under adverse corrosion conditions.

The above fracture mechanics analysis can also be usefully adopted as a basis for design, in applications where brittle components are exposed to severe inservice contact conditions $[2,4,51]$. Thus for sharp, normal contacts eqs (10a) and (10b) may be combined to yield

$$
\sigma_{\mathrm{m}}=\left(3 / 4^{4 / 3} \psi \chi^{1 / 3}\right) K_{\mathrm{c}}^{4 / 3} / P^{1 / 3}
$$

where $P$ is now to be interpreted as the maximum load that is likely to be encountered during the lifetime of the exposed surface. Clearly, if $\sigma_{m}$ falls below the "laboratory strength" of the material, the potential exists for strength degradation. Fortunately, the dependence on $P$ in eq (11) is weak, so the need for detailed information on prospective contact conditions is not great. From the material standpoint, toughness $K_{\mathrm{c}}$ is identified as the parameter to be optimized. It may be noted that an equation of the same form as eq (11) (differing only in the coefficient within the brackets) obtains for the counterpart blunt contact case, as can be seen by combining eq (9) with eq (1). Indeed, the formulation is readily extended to sliding contacts $[21,48]$, or to normal contacts in impact loading $[4,58]$.

Finally, controlled flaws can also be used to measure material parameters to high accuracy, with all the atten- 
dant advantages of simplicity and economy characteristic of indentation methods. For example, by inverting eq (11) one can evaluate $K_{\mathrm{c}}$ in terms of strength and indentation load (given, of course, an appropriate "calibration" of the coefficient in this equation), without any recourse to the measurement of crack dimensions [59]. Similarly, one can combine the $\mathrm{K}$ relation in eq (8) with an appropriate crack velocity function to obtain material-environment fatigue parameters (e.g., exponent $\mathrm{n}$ in power-law velocity function) [53,60-62]. In all these analyses a proper quantitative evaluation requires a full accounting of the residual stress term. The controlled flaw methodology can be extended into the subthreshold region, where important changes in the strength behavior become apparent [27,63-65], although the detailed micromechanical formalisms (the equivalents of eq (8) for crack initiation) have not yet been fully documented.

\section{Erosive Wear and Machining}

The cumulative effect of a large number of surface contacts with small particles can lead to significant amounts of material removal. Of the crack systems discussed in sections 2 and 3 it is the lateral which constitutes the most effective chipping mode [1] (although the cone crack can also be effective in this regard, especially when overlap between adjacent contact sites is frequent). These removal processes can be either highly deleterious or highly beneficial, depending on whether one is seeking to minimize or to maximize the removal process; that is, whether one is concerned with erosive wear [66-69] or with machining [70] properties.

Examples of surface removal damage are shown for soda-lime glass surfaces impacted with sharp silicon carbide particles in figure 19 [69]. The lateral cracking mode is clearly in evidence in the micrographs. In terms of the characteristic surface crack radius $c$ and hardness impression diagonal $a$ (recall that the lateral crack initiates from near the base of the deformation zone, the depth of which scales with $a$ ), we may estimate the potential chip volume for the i'th normal contact event as

$$
V_{\mathrm{i}}=\pi c_{\mathrm{i}}^{2} a_{\mathrm{i}}
$$

This is the entry point for our indentation formalism. The fracture relation eq (5) may then be invoked to eliminate $c_{\mathrm{i}}$, and the conventional hardness relation $P /$ $\alpha a^{2}=H$ ( $\alpha$ a geometrical constant) likewise to eliminate $a_{i}$, from eq (12). Accordingly, we obtain a volume removal equation of the form
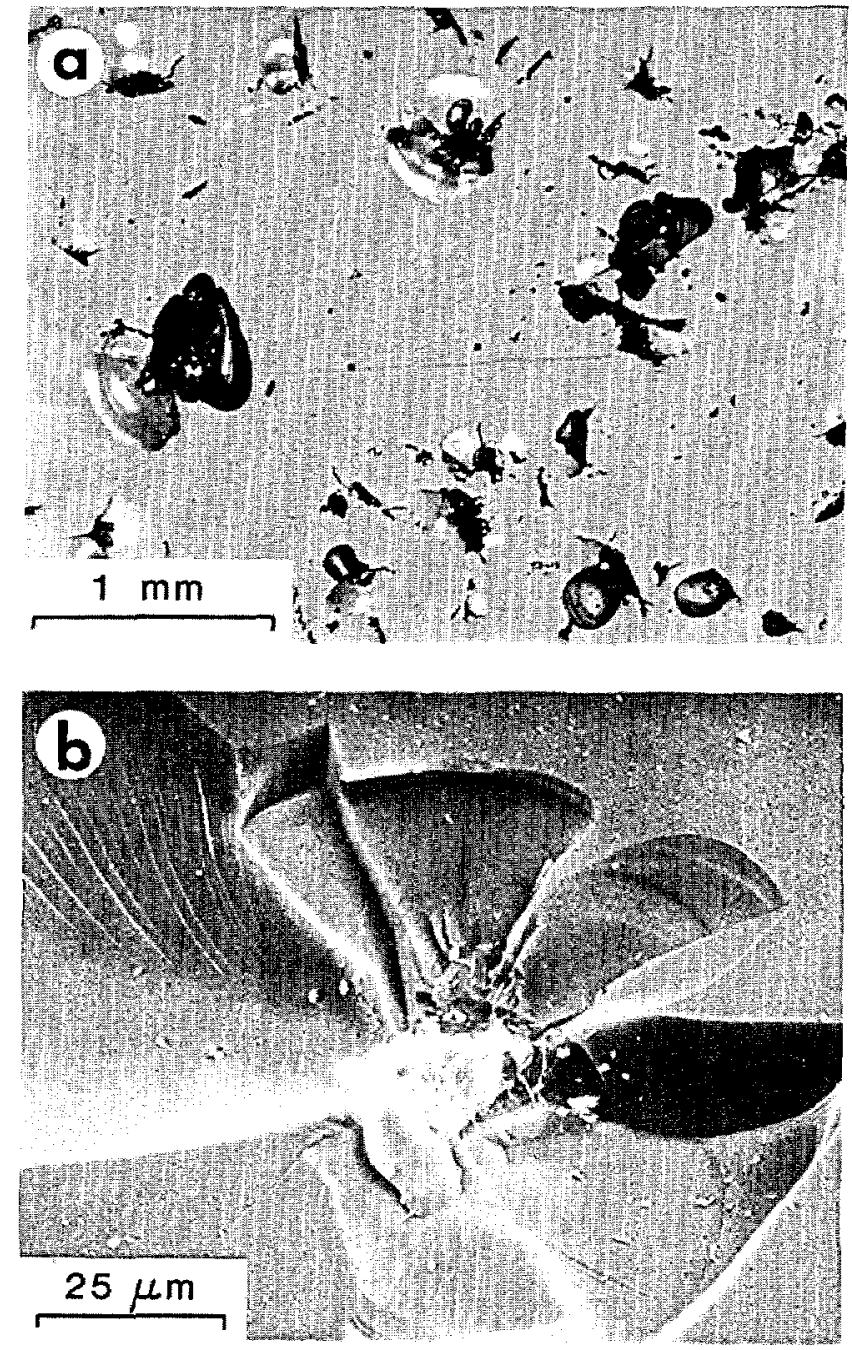

Figure 19-Erosion damage in soda-lime glass impacted with $150 \mu \mathrm{m}$ silicon carbide particles at normally incident velocity $90 \mathrm{~m} \mathrm{~s}^{-1}$ : (a) optical micrograph, showing multiple impact sites; (b) scanning electron micrograph, showing single impact site. Lateral cracking is clearly the dominant surface removal mode. After reference [69].

$$
V_{\mathrm{i}}=\left(\omega / K_{\mathrm{c}}^{4 / 3} H^{1 / 2}\right) P_{\mathrm{i}}^{1 / / 6}
$$

where $\omega=\omega(H / E)$ (recall the dependence of indentation constants on hardness to modulus, Sect. 3.1) is a "wear coefficient." The simplest theories then proceed on the tacit assumption that all such individual contacts are of the same severity and are non-interacting, so that the total volume removed is simply $V=N V$, where $N$ is the number of events. For contacts in impact loading, $P_{i}$ can be eliminated in favor of incident kinetic energy $U_{\mathrm{i}}$ (via an appropriate contact equation) [58] to obtain an erosion equation. The most important predictions of this model, concerning the manner in which the removal rate increases with contact load or energy and decreases 
with material toughness, have been confirmed in extensive experimental studies on erosive wear in brittle glasses and ceramics [66-69].

The procedure for constructing indentation-based models for machining wear rates is basically the same, with due allowance for a tendency to linear rather than point contact geometry. The true nature of machining damage, in terms of the essential interrelation between the near-surface deformation processes and the ensuing cracks, has only recently become clear, primarily as a result of strength studies of the kind referred to in section $4[54,70]$. Development of a detailed theory of machining, with proper account of such important extraneous influences as near-contact lubricants, tool geometry, etc., awaits the next generation of indentation analysts.

\section{References}

[1] Lawn, B. R., and T. R. Wilshaw, Indentation Fracture: Principles and Applications, J. Mater. Sci. 10: 1049 (1975).

[2] Lawn, B. R., and D. B. Marshall, Indentation Fracture and Strength Degradation in Ceramics, in "Fracture Mechanics of Ceramics," R. C. Bradt, D. P. H. Hasselman and F. F. Lange, eds., Plenum Press, New York (1978), Vol. 3, p. 205.

[3] Lawn, B. R., and D. B. Marshall, Mechanisms of Micro-Contact Damage in Brittle Solids, in "Lithic Use-Wear," B. Hayden, ed., Academic Press, New York (1979), p. 63.

[4] Lawn, B. R.; D. B. Marshall, P. Chantikul, and G. R. Anstis, Indentation Fracture: Applications in the Assessment of Strength of Ceramics, J. Aust. Ceram. Soc. 16: 4 (1980).

[5] Lawn, B. R., The Indentation Crack as a Model Indentation Flaw, in "Fracture Mechanics of Ceramics," R. C. Bradt, A. G. Evans, D. P. H. Hasselman, and F. F. Lange, eds., Plenum Press, New York (1983), Vol. 5, p. 1

[6] Lawn, B. R., and S. M. Wiederhorn, Contact Fracture in Brittle Materials, in "Contact Mechanics and Wear of Rail/Wheel Systems," J. Kalousek, R. V. Dukkipati, and G. M. Gladwell, eds., University of Waterloo Press, Vancouver (1983), p. 133.

[7] Lawn, B. R.; B. J. Hockey and H. Richter, Indentation Analysis:Applications in the Strength and Wear of Brittle Materials, J. Microscopy, 130:295 (1983).

[8] Lawn, B. R., Indentation: Deformation and Fracture Processes, in "Strength of Glass," C. R. Kurkjian, ed., Plenum Press, New York, in press.

[9] Hertz, H. H. J. Reine Angew. Math. 92:156 (1881); Verhandlungen des Vereins zur Beforderung des Gewerbe Fleisses 61:449 (1882). Reprinted, in English in "Hertz's Miscellaneous Papers," MacMillan, London (1896), Chs. 5,6.

[10] Frank, F. C., and B. R. Lawn, On the Theory of Hertzian Fracture, Proc. Roy. Soc. Lond. A299:291 (1967).

[11] Roesler, F. C., Brittle Fractures Near Equilibrium, Proc. Phys. Soc. Lond. 69:981 (1956).

[12] Culf, C. J., "Fracture of Glass Under Various Liquids and Gases, J. Soc. Glass Technol. 41:157 (1957).

[13] Williams, J. S.; M. V. Swain and B. R. Lawn, Cone Crack Closure in Brittle Solids, Phys. Stat. Sol. (A) 3:951 (1970).

[14] Lawn, B. R., and E. R. Fuller, Equilibrium Penny-Like Cracks in Indentation Fracture, J. Mater. Sci. 10:2016 (1975).

[15] Langitan, F. B., and B. R. Lawn, Hertzian Fracture Experiments on Abraded Glass Surfaces as Definitive Evidence for an Energy Balance Explanation of Auerbach's Law, $J$. Appl. Phys. 40:4009 (1969).

[16] Warren, R., Measurement of the Fracture Properties of Brittle Solids by Hertzian Indentation, Acta Met. 26:1759 (1978).

[17] Auerbach, F., Measurement of Hardness, Ann. Phys. Chem. 43:61 (1891).

[18] Langitan, F. B., and B. R. Lawn, Effect of a Reactive Environment on the Hertzian Strength of Brittle Solids, J. Appl. Phys. 41:3357 (1970).

[19] Mikosza, A. G., and B. R. Lawn, A Section-and-Etch Study of Hertzian Fracture Mechanics, J. Appl. Phys. 42:5540 (1971).

[20] Lawn, B. R., Hertzian Fracture in Single Crystals with the Diamond Structure, J. Appl. Phys. 39:4828 (1968).

[21] Lawn, B. R.; S. M. Wiederhorn and D. E. Roberts, Effect of Sliding Friction Forces on the Strength of Brittle Solids, $J$. Mater. Sci., in press.

[22] Hamilton, G. M., and L. E. Goodman, The Stress Field Created by a Circular Sliding Contact, J. Appl. Mech. 33:371 (1966).

[23] Lawn, B. R., Partial Cone Crack Formation in a Brittle Material Loaded with a Sliding Spherical Indenter, Proc. Roy. Soc. Lond. A299:307 (1967).

[24] Chiang, S., and A. G. Evans, Influence of a Tangential Force on the Fracture of Two Contacting Elastic Bodies, J. Amer. Ceram. Soc. 66:4 (1983).

[25] Enomoto, Y., Sliding Fracture of Soda-Lime Glass in Liquid Environments, J. Mater. Sci. 16:3365 (1981).

[26] Lawn, B. R., and M. V. Swain, Microfracture Beneath Point Indentations in Brittle Solids, J. Mater. Sci. 10:113 (1975).

[27] Dabbs, T. P.; D. B. Marshall and B. R. Lawn, Flaw Generation by Indentation in Glass Fibers, J. Amer. Ceram. Soc. 63:224 (1980).

[28] Marshall, D. B., and B. R. Lawn, Residual Stress Effects in Sharp-Contact Cracking: I. Indentation Fracture Mechanics, J. Mater. Sci. 14:2001 (1979).

[29] Ishikawa, H., and N. Shinkai, Critical Load for Median Crack Indentation in Vickers Indentation of Glasses, J. Amer. Ceram. Soc. 65:C-124 (1982).

[30] Lawn, B. R.; T. P. Dabbs and C. J. Fairbanks, Kinetics of Shear-Activated Indentation Crack Initiation in Soda-Lime Glass, J. Mater. Sci. 18:2785 (1983).

[31] Marshall, D. B., and A. G. Evans, Reply to Comment on Elastic/Plastic Indentation Damage in Ceramics: The Median/Radial Crack System, J. Amer. Ceram. Soc. 64:C-182 (1981).

[32] Evans, A. G., and T. R. Wilshaw, Quasi-Static Solid Particle Damage in Brittle Solids, Acta Met. 24:939 (1976).

[33] Marshall, D. B.; B. R. Lawn and A. G. Evans, Elastic/Plastic Indentation in Ceramics: The Lateral Crack System, $J$. Amer. Ceram. Soc. 65:561 (1982).

[34] Lawn, B. R., and V. R. Howes, Elastic Recovery of Hardness Indentations, J. Mater. Sci. 16:2475 (1981).

[35] Marshall, D. B.; T. Noma and A. G. Evans, A Simple Method for Determining Elastic-Modulus to Hardness Ratios Using Knoop Indentation Measurements, J. Amer. Ceram. Soc. 65:C-175 (1982).

[36] Arora, A.; D. B. Marshall, B. R. Lawn, and M. V. Swain, Indentation Deformation/Fracture of Normal and Anomalous Glasses, J. Non-Cryst. Solids 31:915 (1979).

[37] Lawn, B. R.; A. G. Evans and D. B. Marshall, Elastic/Plastic Indentation Damage in Ceramics: The Median/Radial 
Crack System, J. Amer. Ceram. Soc. 63:574 (1980).

[38] Hockey, B. J., unpublished work.

[39] Cottrell, A. H., Theory of Brittle Fracture in Steel and Similar Metals, Trans. Met. Soc. A.I.M.E. 212:192 (1958).

[40] Lawn, B. R., and T. R. Wilshaw, "Fracture of Brittle Solids," Cambridge University Press, London (1975), Ch. 2.

[41] Hagan, J. T., and M. V. Swain, The Origin of Median and Lateral Cracks at Plastic Indents in Brittle Materials, $J$. Phys. D: Appl. Phys. 11:2091 (1978).

[42] Hagan, J. T., Shear Deformation Under Pyramidal Indentations in Soda-Lime Glass, J. Mater. Sci. 15:1417 (1980).

[43] Dabbs, T. P.; C. J. Fairbanks and B. R. Lawn, Subthreshold Indentation Flaws in the Study of Fatigue Properties of Ultra-High Strength Glass, in "Methods for Assessing the Structural Reliability of Brittle Materials," S. W. Freiman, ed., ASTM Special Technical Publication, in press.

[44] Lawn, B. R., and A. G. Evans, A Model for Crack Initiation in Elastic/Plastic Indentation Fields, J. Mater. Sci. 12:2195 (1977).

[45] Multhopp, H.; B. R. Lawn and T. P. Dabbs, DeformationInduced Crack Initiation by Indentation of Silicate Materials, in Plastic Deformation of Ceramic Materials, R. E. Tressler and R. C. Bradt, eds., Plenum Press, New York, in press.

[46] Ernsberger, F. M., Mechanical Properties of Glass, J. NonCryst. Solids 25:293 (1977).

[47] Anstis, G. R.; P. Chantikul, D. B. Marshall, and B. R. Lawn, A Critical Evaluation of Indentation Techniques for Measuring Fracture Toughness: I. Direct Crack Measurements, J. Amer. Ceram. Soc. 64:533 (1981).

[48] Symonds, B. L.; R. F. Cook and B. R. Lawn, Dynamic Fatigue of Brittle Materials Containing Indentation Line Flaws, $J$. Mater. Sci. 18:1306 (1983).

[49] Swain, M. V., Median Crack Initiation and Propagation Beneath a Disc Glass Cutter, Glass Technol. 22:222 (1981).

[50] Marshall, D. B., Controlled Flaws in Ceramics: A Comparison of Knoop and Vickers Indentation, J. Amer. Ceram. Soc. 66:127 (1983).

[51] Marshall, D. B.; B. R. Lawn and P. Chantikul, Residual Stress Effects in Sharp-Contact Cracking: II. Strength Degradation, J. Mater. Sci. 14:2225 (1979).

[52] Marshall, D. B., Mechanisms of Failure From Surface Flaws in Mixed Mode Loading, J. Amer. Ceram. Soc., in press.

[53] Marshall, D. B., and B. R. Lawn, Flaw Characteristics in Dynamic Fatigue: The Influence of Residual Contact Stresses, J. Amer. Ceram. Soc. 63:532 (1980).

[54] Marshall, D. B., Failure From Surface Flaws, in "Methods for Assessing the Structural Reliability of Brittle Materials," S. W. Frieman, ed., ASTM Special Technical Publication, in press.
[55] Marshall, D. B; B. R. Lawn and J. J. Mecholsky, Effect of Residual Contact Stresses on Mirror/Flaw-Size Relations," J. Amer. Ceram. Soc. 63:358 (1980).

[56] Mould, R. E., Strength and Static Fatigue of Abraded Glass Under Controlled Ambient Conditions: III. Aging of Fresh Abrasions," J. Amer. Ceram. Soc. 43:160 (1960).

[57] Marshall, D. B., and B. R. Lawn, Surface Flaws in Glass, in "Strength of Glass," C. R. Kurkjian, ed., Plenum Press, New York, in press.

[58] Wiederhorn, S. M., and B. R. Lawn, Strength Degradation of Glass Impacted With Sharp Particles: I. Annealed Surfaces, J. Amer. Ceram. Soc. 62:66 (1979).

[59] Chantikul, P.; G. R. Anstis, B. R. Lawn, and D. B. Marshall, A Critical Evaluation of Indentation Techniques for Measuring Fracture Toughness: II. Strength Method, J. Amer. Ceram. Soc. 64:539 (1981).

[60] Chantikul, P.; B. R. Lawn and D. B. Marshall, Micromechanics of Flaw Growth in Static Fatigue: Influence of Residual Contact Stresses, J. Amer. Ceram. Soc. 64:322 (1981).

[61] Lawn, B. R.; D. B. Marshall, G. R. Anstis, and T. P. Dabbs, Fatigue Analysis of Brittle Materials Using Indentation Flaws: I. General Theory, J. Mater. Sci. 16:2846 (1981).

[62] Cook, R. F.; B. R. Lawn and G. R. Anstis, Fatigue Analysis of Brittle Materials Using Indentation Flaws: II. Case Study on a Glass Ceramic, J. Mater. Sci. 17:1108 (1982).

[63] Dabbs, T. P.; B. R. Lawn and P. L. Kelly, A Dynamic Fatigue Study of Soda-Lime and Borosilicate Glasses Using SmallScale Indentation Flaws, Phys. Chem. Glasses 23:58 (1982).

[64] Dabbs, T. P., and B. R. Lawn, Fatigue of High-Strength SodaLime Glass: A Constant Stressing Rate Study Using Subthreshold Flaws, Phys. Chem. Glasses 23:93 (1982).

[65] Dabbs, T. P., and B. R. Lawn, Acid-Enhanced Crack Initiation in Glass, J. Amer. Ceram. Soc. 65:C-37 (1982).

[66] Evans, A. G.; M. E. Gulden and M. E. Rosenblatt, Impact Damage in Brittle Materials in the Elastic-Plastic Response Regime, Proc. Roy. Soc. Lond. A361:343 (1978).

[67] Hockey, B. J.; S. M. Wiederhorn and H. Johnson, Erosion of Brittle Materials by Solid Particle Impact, in "Fracture Mechanics of Ceramics," R. C. Bradt, D. P. H. Hasselman, and F. F. Lange, eds., Plenum Press, New York (1978), Vol. 3, p. 379.

[68] Gulden, M. E., Correlation of Experimental Erosion Data With Elastic-Plastic Impact Models, J. Amer, Ceram. Soc. 64:C-59 (1981).

[69] Wiederhorn, S. M., and B. J. Hockey, Effect of Material Parameters on the Erosion Resistance of Brittle Materials, $J$. $M a$ ter. Sci. 18:766 (1983).

[70] Marshall, D. B.; A. G. Evans, B. T. Khuri-Yakub, J. W. Tien, and G. S. Kino, The Nature of Machining Damage in Brittle Materials, Proc. Roy Soc. Lond. A385:461 (1983). 